\title{
Assessment of Efficacy of Hayman Suture Technique in Management of Intraoperative Atonic Postpartum Hemorrhage
}

\author{
DRAKHSHAN NAUMAN, NADIA SAIF, UZMA SIDDIQUE, NOSHEEN NAVEED \\ QURAT-UL-AIAN MUNIR, NAHEED JAMAL FARUQI, FAREEHA FAROOQ \\ Department of Gynecology, Akhtar Saeed Medical and Dental College, Lahore - Pakistan
} DOI 10.36552/pjns.v24i2.447

\begin{abstract}
Objective: To assess the efficacy of the Hayman suture technique in the management of intraoperative atonic postpartum hemorrhage thus reducing maternal morbidity and mortality.

Study Design: Simple Descriptive study.

Materials and Method: A simple descriptive observational study was conducted at Farooq Hospital and AIT, Lahore. The study included all patients with intraoperative atonic PPH after elective and emergency caesarean sections, during the study period, in whom medical management of PPH failed and Hayman suture was applied.

Results: Hayman suture was $97.5 \%$ successful in controlling primary PPH due to intraoperative uterine atony. It failed in only one patient (2.5\%) and that patient needed a hysterectomy.

Conclusion: Hayman suture is an effective and quick technique in controlling primary PPH due to intraoperative uterine atony. It is an effective surgical technique after failure of conservative medical management. It is easy to apply and can be applied by Postgraduate trainees and registrar in emergency as lifesaving procedure.
\end{abstract}

Keywords: Atonic uterus, Postpartum hemorrhage (PPH), Hayman suture (modified B-Lynch suture).

\section{INTRODUCTION}

Excessive vaginal bleeding from female genital tract after delivery of the baby is Postpartum Hemorrhage. According to W.H.O, primary PPH is defined as postpartum blood loss of $\geq 500 \mathrm{ml}$ after vaginal birth and $\geq 1000 \mathrm{ml}$ after caesarean section, within 24 hours of delivery. ${ }^{1}$ Worldwide incidence of $\mathrm{PPH}$ is $5 \% .{ }^{2}$ Risk of maternal death due to PPH is 1 in 1000 indeveloping countries and 1 in 100,000 in developed countries. ${ }^{3}$ Primary PPH is a major cause of maternal deaths especially in developing countries. ${ }^{4}$ In Pakistan, major Obstetric hemorrhage is leading cause of maternal mortality, accounting for $27.2 \%$ maternal deaths. ${ }^{5}$

Etiology of PPH is divided into 4 categories and uterine atony is the most common cause, being observed in $70-80 \%$ cases of PPH. ${ }^{6,7}$ Other causes include genital tract trauma $(8 \%)$, retained products of conception (5\%) and Coagulopathy $(2 \%)^{7,8}$

Caesarean section is a well-known risk factor for $\mathrm{PPH}$ and the incidence of caesarean section is also increasing worldwide. ${ }^{9}$

The usual medical management of PPH includes uterine massage and bimanual compression, uterotonic agents (Oxytocin, PGE1), uterine balloon tamponade and arterial embolization. Failure of medical management necessitate the use of surgical interventions like ligation of major blood vessels and hysterectomy, both of these procedures require skills and expertise and are time consuming.

In 1997, Balogun Lynch Christopher introduced the use of uterine compression sutures to treat uterine atony. This technique needed incision of lower uterine segment after bladder dissection. This technique had been used successfully worldwide. ${ }^{10}$

In 2002, Richard Hayman modified and simplified 
this procedure. ${ }^{11}$ Hayman (Modified B-Lynch) suture does not require an incision of lower uterine segment, so it is easy to apply and less time consuming.

This study was conducted to assess the efficacy of Hayman suture during intraoperative uterine atony and thus managing PPH timely.

\section{MATERIAL AND METHODS}

\section{Study Design}

This simple descriptive observational study was conducted in the Department of Obstetrics and Gynecology, Farooq teaching Hospital, Allama Iqbal Town, Lahore, affiliated with the Akhtar Saaed Medical and Dental College, Lahore. The study period was of two years, from JAN 2017 to DEC 2018.

\section{Data Collection}

All information entered on pre-designed proforma. During this study period, total 932 cesarean sections were performed (emergency and elective both). 40 patients undergoing elective or emergency caesarean section had primary PPH due to intraoperative uterine atony which was non responsive to medical therapy so Hyman stitch applied after test of potential success was fulfilled. This test was simple bimanual compression of the exteriorized uterus for a few minutes and assessing reduction of blood loss vaginally. If bleeding controlled, then Hayman stitch was successful and if the patient needed hysterectomy then Hayman stitch was considered as failed.

Estimation of blood loss was done bythe amount of blood loss from vagina, sponges and sheets soaked with blood, the amount of blood in suction bottle, and hemodynamic instability of the patient.

\section{Inclusion Criteria}

All women undergoing elective or emergency caesarean sections and diagnosed as case of primary $\mathrm{PPH}$ due to intraoperative uterine atony, were included.

\section{Exclusion Criteria}

All women with Placenta previa, Placental abruption, disseminated intravascular Coagulation and HELLP syndrome were excluded.

\section{Hayman Suture Technique}

Uterine scar was closed with Vicryl 1 round body needle, in 2 layers as per routine. First layer of continuous locking sutures and second layer of nonlocking embedding sutures were applied and hemostasis secured.

Uterus was then exteriorized and bimanual compression done as test of potential efficacy to control PPH. If bimanual compression achieved uterine tone and vaginal bleeding controlled, then the decision to apply Hayman suture was made.

Hayman stitch was applied using Chromic catgut no 1 on straight needle. The needle was passed from an anterior surface of uterus in lower uterine segment $2 \mathrm{~cm}$ beneath uterine scar and above bladder reflection, it traversed full thickness of the uterine wall and came out on posterior surface of the uterus on the same level and held there with an artery forceps. Two such stitches were applied on each side of the uterus and held there (Figure $1 \mathrm{~A}$ ).

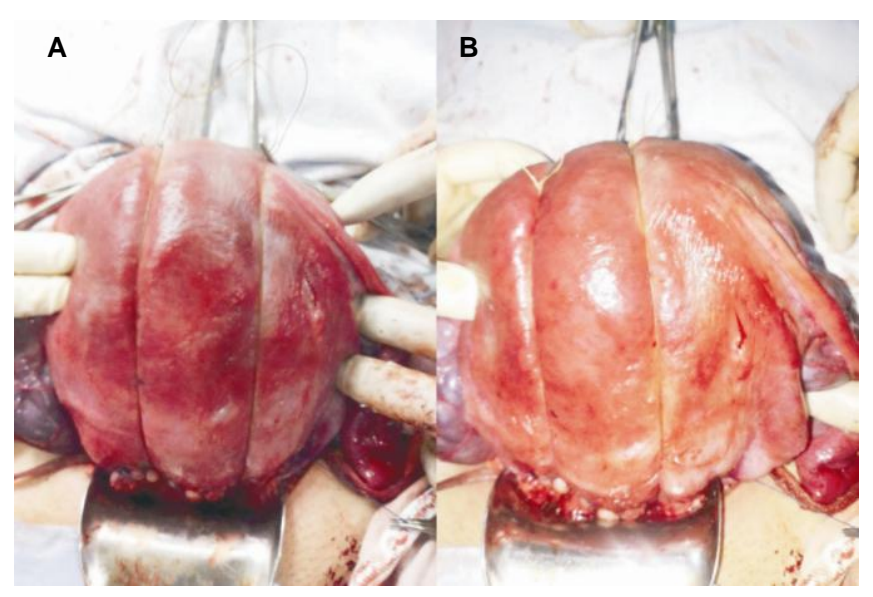

Fig. 1: A (left) Hayman stitch applied at two points. $B$ (right): Knot applied at fundus of uterus.

An assistant compressed the uterus bimanually and knot of each suture was tied at the fundus of uterus tightly one by one thus producing bimanual compression (Fig.1 B). If bleeding controlled and the patient improved hemodynamically, abdominal cavity closed and need for blood transfusion assessed according to the preoperative Hemoglobin level and intraoperative blood loss. Patient closely monitored for 24 hours postoperatively. Postoperative complications noted and the patient discharged on the $3^{\text {rd }}$ postop day and called back on the $8^{\text {th }}$ postop day for stitch removal. 


\section{Data Analysis}

Data analysis was done using SPSS version 22. Frequencies and percentage calculations were done for qualitative variables.

\section{RESULTS}

During the study period, 932 caesarean sections done and 40 patients needed Hayman suture to control primary PPH.

\section{Age Incidence}

Majority patients were in the age group $20-30$ years $(\mathrm{n}=27,67.5 \%) .9$ patients $(22.5 \%)$ were $>30$ years old and 4 patients (10\%) were less than 20 years old.

\section{Clinical Data}

Out of 40 patients included in the study, 29 patients $(72.5 \%)$ undergoing emergency caesarean section had $\mathrm{PPH}$ as compared to 11 patients $(27.5 \%)$ undergoing elective caesarean sections and landing into PPH. So it was concluded that the risk of $\mathrm{PPH}$ is higher in emergency caesarean sections as compared to elective surgeries.

When parity of these patients compared, it was found out that 7 patients $(17.5 \%)$ were primigravida, 3 patients $(7.5 \%)$ were para 1 and para 3 each, 5 patients (12.5\%) were para 2 and total 22 patients $(55 \%)$ were $\geq$ para 4.So it was concluded that increased parity increased chance of uterine atony.

Amount of blood loss was noted in all patients and showed in Table 1.22 patients (55\%) had blood loss between $1000 \mathrm{ml}-1300 \mathrm{ml}$.

Table 1: Amount of Blood Loss $(n=40)$.

\begin{tabular}{|l|c|c|}
\hline Blood Loss $(\mathbf{m l})$ & Number $(\mathbf{n}=\mathbf{4 0})$ & Percentage $(\boldsymbol{\%})$ \\
\hline $1000-1300 \mathrm{ml}$ & 22 & 55 \\
\hline $1301-1600 \mathrm{ml}$ & 11 & 27.5 \\
\hline $1601-2000 \mathrm{ml}$ & 07 & 17.5 \\
\hline
\end{tabular}

Need for blood transfusion depended on the preoperative hemoglobin level and intraoperative blood loss. 18 patients $(45 \%)$ did not require blood transfusion.9 patients $(22.5 \%)$ needed transfusion of 1 unit blood, 8 patients (20\%) needed 2 units blood transfusion and only 5 patients $(12.5 \%)$ needed $\geq 3$ blood transfusions.

Time taken to apply Hayman suture is shown in table 2. In most of the patients $(\mathrm{n}=18,45 \%)$ Hayman stitch was applied in less than 10 minutes.

Table 2: Time taken to apply Hayman Suture $(n=40)$.

\begin{tabular}{|l|c|c|}
\hline Time Taken (Minutes) & $\begin{array}{c}\text { No of Patients } \\
(\mathbf{n}=\mathbf{4 0})\end{array}$ & Percentage (\%) \\
\hline$<10 \mathrm{~min}$ & 18 & 45 \\
\hline $11-20 \mathrm{~min}$ & 17 & 42.5 \\
\hline$>20 \mathrm{~min}$ & 05 & 12.5 \\
\hline
\end{tabular}

\section{Outcome}

Efficacy of Hayman suture was assessed and shown in table 3. It was declared successful if PPH controlled and it was failed if patient landed into hysterectomy. In our study $(n=39,97.5 \%)$ had successful Hayman suture in controlling PPH and it failed in only 1 patient (2.5\%) who needed a hysterectomy as lifesaving procedure.Fortunately, no mortality in our study.

Table 3: Success of Hayman Suture $(n=40)$.

\begin{tabular}{|l|c|c|}
\hline Success & Number (n) & Percentage (\%) \\
\hline Yes & 39.0 & 97.5 \\
\hline No (Hysterectomy needed) & 1.0 & 2.5 \\
\hline Total & 40.0 & 100 \\
\hline
\end{tabular}

\section{Complications}

Postoperative complications were also noted in all patients. Only 3 patients $(7.5 \%)$ had fever, 2 patients (5\%) suffered from mild abdominal pain and only 1 patient $(2.5 \%)$ had infected wound.

\section{DISCUSSION}

Uterine brace sutures are an effective mean to control PPH resulting from uterine atony.It also reduced the morbidity resulting from hysterectomy. Modified B Lynch suture (Hayman suture) is simple and quick method so even residents and registrars can apply it timely in case of emergency to save the life of mother.

Many studies on efficacy of compression suture in intraoperative atonic $\mathrm{PPH}$, have been done. ${ }^{12}$ However $1^{\text {st }}$ population based large scale study was done in UK to observe increasing trends in atonic PPH in Ireland 
and this increasing rate of PPH highlighted the need for clinical audit of etiology and preventive measures. The study span was 11 years and it was published in BJOG in 2012. ${ }^{13}$

Our study included 40 patients with intraoperative atonic PPH after elective and emergency caesarean sections.

Most of the patients in our study who needed Brace suture were having the age range of $20-30$ years. This is comparable to study done in Jinnah hospital in 2011, where $70 \%$ cases of PPH were in the age range of $20-30$ years. ${ }^{14}$ However, another study concluded that only $31.25 \%$ patients were in the age range of $20-30$ years. ${ }^{15}$

Regarding parity of patients, most cases of PPH in our study $(55 \%)$ occur in women with parity $\geq 4$. This is in contrast to another study where only $21.7 \%$ patients with PPH were having parity $>4 .{ }^{14}$

Most of the patients having PPH were delivered by emergency caesarean section. $(n=29,72.5 \%)$. These results are comparable with a local study in which $76 \%$ patient delivered by emergency caesarean section suffered from PPH. ${ }^{16}$

Excessive blood loss due to uterine atony in our study was also compared with other studies. Most of the patients in our study ( $\mathrm{n}=22,55 \%)$ had blood loss between $1000-1300 \mathrm{ml}$. Contrasting results were shown by a local study where $62.2 \%$ patients had blood loss between $1500 \mathrm{ml}-200 \mathrm{ml}^{17}$

Need for blood transfusion depended on the preoperative hemoglobin level and intraoperative blood loss. In our study, $45 \%$ patients did not require blood transfusion. Contrasting results are shown by other studies. ${ }^{16,18}$

As Hayman stitch is less time consuming and doesnot require to convert unscarred uterus into scarred uterus, less time is required to apply this.In our study, it was applied in $<10 \mathrm{mins}$ in $50 \%$ patients. This is comparable to another study by an Indian author. ${ }^{18}$ However; contrasting results were shown by Anamika et al in which only $7 \%$ patients took less than 10 minutes in suture application. ${ }^{19}$

Efficacy of Hayman suture in our study is defined by control of PPH and saving the patient from hysterectomy. Therefore, the success rate in our study is $97.5 \%$. $(\mathrm{n}=39) .100 \%$ success rate was described by Anamika et al ${ }^{19}$ and Hackenthal et al. ${ }^{20}$

Fewer postoperative complications were noted in our study. Only $7.5 \%$ patients had fever, $5 \%$ had abdominal pain and $2.5 \%$ had wound infection. These results were comparable to another study where $4 \%$ patient had fever and $2 \%$ had gaped wound. ${ }^{16}$ Contrasting results were shown by another study where $44.5 \%$ patients receiving B-Lynch suture suffered from fever and $11 \%$ had gaped wound. ${ }^{15}$

\section{CONCLUSION}

Our study concluded that Hayman suture is safe, effective, quick and easy surgical procedure for controlling PPH due to intraoperative uterine atony.It is easy to apply and doesnot need to convert unscarred uterus into scarred uterus. It can be applied by duty registrar and trainees in emergency as lifesaving procedure. All postgraduate residents and registrars should learn this skill. Larger scale studies are needed to further strengthen its efficacy.

\section{REFERENCES}

1. Royal College of Obstetrics and Gynecology. Prevention and management of post-partum hemorrhage. Green Top Guideline No. 52. London: RCOG; 2011.

2. Lu M C, Fridman M, Korst L M et al. Variations in the incidence of postpartum hemorrhage across hospitals in California. Matern Child Health. J. 2005; 9: 297-306. [Pubmed]

3. Mousa H A, Alfirevic Z. Treatment for primary postpartum hemorrhage. Cochrane Database Syst Rev. 2003; (1): CD003249-.[Pubmed]

4. WHO recommendations for the prevention and treatment of postpartum hemorrhage, 2012.

5. Naz H, Sarwar I, Fawad A, Nisa AU. Maternal morbidity and mortality due to primary $\mathrm{PPH}-$ experience at Ayub Teaching Hospital Abbottabad. J Ayub Med Coll Abbottabad, 2008; 20 (2): 59-65.

6. NHS Scotland. Scottish confidential audit of severe maternal morbidity. $7^{\text {th }}$ Annual Report, 2011.

7. Wetta A, Jeff M, et al. Risk factors for uterine atony requiring treatment after vaginal delivery. AJOG. 2013; 209 (1): 51.

8. Doumouchtsis, Stergois K, Sabaratnam A. Systemic review of conservative management of postpartum hemorrhage: What to do when medical treatment fails. Obstet \& Gynecol. Survey, 2007; 62 (8): 540-547.

9. Villar J, Valladares E, Wojdyla D, Zabaleta N, Carroli G, Velazco A, et al (2005). Caesarean delivery rates and pregnancy outcomes : the 2005 WHO global survey on maternal and perinatal health in Latin America.Lancet. 2006; 367: 1819-29.

10. Koh E, Devendra K, Tanl. B-Lynch suture for the treatment of uterine atony. Singapore Meds. 2009; 50 (7): 693-7. 
11. Ghodake V B, Pandit S N, Umbardand S M. Role of modified B-Lynch suture in modern day management of atonic PPH. Bombay Hospital Journal, 2008; 50 (2): 205-10.

12. Marasinghe JP, Condous G, Uterine compression sutures for the post-partum bleeding with atony; modification of the B-Lynch. Aust NZ Obstet Gynecol. 2009; 49: 67-70.

13. Lutorrski JE, Byme BM, Devore D.Increasing trends in atonic PPH IN Ireland: an 11 year population based study. BJOG. 2012; 119: 306-14.

14. Tariq S, Wazir S, Moeen G. Efficacy of B-Lynch Suture in Postpartum Hemorrhage. Annals, 2011; 17 (2): 116-122.

15. Bhutta FN, Bhutta MMK, Bhutta J, Ali R, Tahir S, Aleem M. A stitch in Time, Saves Life ; Should BLynch suture be the First Line Surgical Option for Control of Massive Primary PPH due to Refractory Uterine Atony? An Experience at D.H.Q Hospital Faisalabad. A.P.M.C. 2015; 9 (2): 71-78.

16. Fatima T, Kousar S, Mohsin B, Tabassum Z.
Effectiveness of Single Compression Suture in Management of Atonic Uterus during C-Section. PJMHS. 2018; 12 (2): 681-683.

17. Faruqi NJ, Javed L, Yousaf F.B-lynch suture for the management of postpartum haemorrhage- a local experience. Ann King Edward Med Coll. 2004; 10: 370-3.

18. Kalyankar V, Yelikar K, Kulsange P. Assessment of efficacy of Modified Balogun Lynch-Stitch in management of Atonic Postpartum Hemorrhage. IJBAR. 2014; 5 (5): 258-61.

19. Majumdar A, Malick K, Vasava B, Desai KT, Dalal M. A descriptive study on Hayman suture technique to control postpartum hemorrhage. Sri Lanka J Obstet Gynecol. 2012; 34: 79-83.

20. Hackethal A, Bruggmann D, Oehmke F, Tinneberg HR. Uterine compression sutures in primary $\mathrm{PPH}$ after Caesarean section. Fertility Preservation with a simple and effective technique. Human Reprod. 2008; 23 (1): 74-9.

\section{Additional Information}

Disclosures: Authors report no conflict of interest.

Ethical Review Board Approval: The study was conformed to the ethical review board requirements.

Human Subjects: Consent was obtained by all patients/participants in this study.

Conflicts of Interest:

In compliance with the ICMJE uniform disclosure form, all authors declare the following:

Financial Relationships: All authors have declared that they have no financial relationships at present or within the previous three years with any organizations that might have an interest in the submitted work.

Other Relationships: All authors have declared that there are no other relationships or activities that could appear to have influenced the submitted work.

Date of Submission: 20-4-2020

Address for Correspondence:

Date of Revision: 23-05-2020

Drakhshan Nauman

Date of Online Publishing: 30-06-2020

Date of Print: 30-07-2020

Department of Gynae/Obst

Akhtar Saeed Medical and Dental College, Lahore - Pakistan

Email:drdrakhshan@yahoo.com

\section{AUTHORSHIP AND CONTRIBUTION DECLARATION}

\begin{tabular}{|l|l|l|}
\hline Sr.\# & Author's Full Name and Affiliation & Intellectual Contribution to Paper in Terms of: \\
\hline 1. & Nadia Saif & Study design and methodology. \\
\hline 2. & Drakhshan Nauman & Paper writing, referencing, data calculations and \\
\hline 3. & Uzma Siddique, Qurat-ul-Aian Munir & Data collection and calculations \\
\hline 4. & Nosheen Naveed & Analysis of data and interpretation of results etc. \\
\hline 5. & Drakhshan Nauman & Literature review and manuscript writing. \\
\hline 6. & Naheed Jamal Faruqi & Analysis of data and quality insurer. \\
\hline 7. & Fareeha Farooq & Final review of Article. \\
\hline
\end{tabular}

